\title{
EL URBANISMO SECUENCIAL COMO INSTANCIA SUPERADORA DEL URBANISMO PENDULAR
}

\section{Daniela Szajnberg}

Arquitecta-UBA (1992). Magíster en Planificación Urbana y Regional-UBA (especialista: 1999; magíster: 2007). Profesora de grado y posgrado e investigadora de FADU-UBA. Directora del Proyecto de Investigación UBACyT 100129. Consultora de organismos públicos y organizaciones no gubernamentales.

\section{Christian Cordara}

Arquitecto-UBA (2003). Especialista en Planificación Urbana y Regional - UBA (2009). Docente en grado de Planificación Urbana desde 2009. Profesor adjunto en las materias Arquitectura y Proyecto Urbano desde 1997. Profesor titular en Licenciatura en Gestión Ambiental Urbana - UNLA. Investigador del Programa Urbanismo y Ciudad desde 2003.

\section{Noel Luna}

Arquitecta UBA. Especialista en Planificación Urbana y Regional. Docente en grado de Planificación Urbana. Investigadora en el Proyecto UBACyT 100129. Asesora y coordinadora de procedimientos de gestión y factibilidad de proyectos urbanos. Management de proyectos arquitectónicos en el ámbito privado desde 1997. Consultora sobre desarrollo sustentable y medio ambiente.

\section{Carina Bories}

Profesora de Enseñanza Secundaria, Normal y Especial en Geografía UBA 1992. Posgrado en Gestión y Planificación Urbana, CAPBA Distrito II, 1998. Especialista en Planificación Urbana y Regional, FADU-UBA. Docente en instituciones del nivel medio de enseñanza y terciarios de la carrera de Geografía y Ciencias Sociales. Docente en grado de Planificación Urbana. Investigadora en el Proyecto UBACyT 100129.

\section{Colaboradores: Florencia Atadía, Guillermina Jáuregui, Bárbara Stern, Gabriel Perazzi}




\section{Resumen}

Desde las políticas públicas se incide en los procesos de producción, uso y apropiación del territorio, interviniendo en su valorizacion y estableciendo las condiciones para el desarrollo urbano. El sentido, la magnitud y la intensidad de dichas políticas determinan también los patrones de evolución socioterritorial.

La ciudad crece sometida a avatares ocasionados por la dialéctica contrapuesta entre esas políticas y el proceso de urbanización, sorteando fases que tienden a alternarse y reiterarse en una suerte de Urbanismo Pendular.

Reconocer sus rasgos resulta clave en procura de potenciar lo positivo y no replicar lo negativo. Un posible camino es el de asimilar, junto con las regularidades de esas tendencias, la complejidad e incertidumbre que la multiplicidad de variables confieren al hecho urbano, procurando saltear los inmutables escenarios positivistas, por un abordaje procesual y dinámico, apostando a conformar un urbanismo superador, como podría serlo el Urbanismo Secuencial.

\section{Abstract}

Public policies influence production processes, use and appropriation of territory, intervening in its valorization and establishing conditions for urban development. The direction, magnitude and intensity of these policies also determine patterns of socio-territorial development.

A city grows as a result of the ups and downs caused by the dialectical relationship between these policies and the urbanization process, bypassing stages that tend to alternate and repeat themselves in a kind of Urban Pendulum.

Recognizing its features is the key to attempt to enhance the positive and avoid the negative trends. A possible way is to assimilate the regularities of these trends with the complexity and uncertainty that the multiplicity of variables give the urban phenomenon, trying to skip over the immutable positivist scenarios, through a procedural and dynamic approach, betting on a pattern that can overcome "pendular urbanism" replacing it a by a form of "sequential urbanism".

Palabras clave

Producción, uso y apropiación del territorio, política urbanística y procesos de urbanización, Urbanismo Pendular, Urbanismo Secuencial.

Keywords

Production, use and appropriation of territory / Urban Policy and urbanization processes / Pendular and Sequential urbanism. 


\section{INTRODUCCIÓN}

La ciudad es consecuencia de una sucesión de procesos culturales definidos según los modos de producción, uso y apropiación del territorio (CASTELLS, 1972). Estos procesos operan transformaciones condicionados por prácticas urbanas de actores sociales y conflictos por su competencia de intereses, lo que se procura solucionar a través de las políticas públicas como la planificación urbana, con resultados diversos.

Sin incurrir en planteos extremistas como el de Peter Hall, quien sostiene que transcurridos más de dos siglos desde la Revolución Industrial, el Urbanismo ha terminado "mordiéndose la cola" (HALL, 1996), sin haber coadyuvado a superar la realidad, entrado el nuevo siglo, podemos decir que si bien gran parte de los problemas urbanos se han reconocido y se construyen alternativas de soluciones, otros tantos continúan sin resolverse o agudizándose.

En ese sentido pueden construirse dos lecturas del fenómeno urbano. Por un lado las prácticas urbanas, que analizadas en sentido evolutivo, dan cuenta de los modos de producir la ciudad. Por otro, comportamientos de carácter periódico dentro de las políticas públicas, que conforman los modos de gestionar sobre la ciudad.

Tras un recorrido con foco en las manifestaciones de las prácticas urbanas en relación con las políticas públicas urbanísticas, tomando como caso la metrópolis de Buenos Aires, en este artículo se parte de la hipótesis de que la evolución disciplinar, tanto como la práctica política en el campo del Urbanismo y la Planificación Urbana transitan un camino cíclico. Tal analogía responde al hecho de haber identificado procesos de urbanización y políticas urbanísticas que oscilan en torno de un eje de equilibrio, desplazándose con movimientos periódicos, siguiendo patrones repetitivos, emulando el vaivén de un péndulo, constituyendo un tipo de Urbanismo "Pendular" (UP).

El contexto histórico resulta determinante en este tipo de procesos dinámicos. Por ejemplo, cuando ese contexto estuvo contenido por las políticas del Estado Benefactor y el Desarrollismo, el proceso de suburbanización mediante el cual la ciudad se expandió hacia mediados del siglo XX produjo una urbe donde prevalecía el interés por la construcción del espacio público; contrariamente al proceso de suburbanización actual, en el que predomina la apropiación privada del espacio. Más que el espacio característico del tejido continuo de sectores medios y medio bajos con que se desarrolló el conurbano en aquel contexto, el tipo de espacio protagonista de estos nuevos procesos ha sido el de tipo enclave, característico de los rangos sociohabitacionales y socioeconómicos extremos. 
En ambos procesos el Estado actuó con acciones sectoriales y fragmentadas, en general sobre hechos consumados, o con ausencia de previsiones de largo plazo, dándose poco lugar a la política urbana explícita. Para el Área Metropolitana de Buenos Aires (AMBA) en su conjunto se han sucedido planes con repercusión parcial y las inversiones públicas han sido sectoriales. Existió una preocupación por la cuestión urbana, en particular a partir de los años 40 del siglo XX, época de gran crecimiento poblacional, y actividades productivas encuadradas en la industrialización por sustitución de importaciones. Ese crecimiento dinámico e inorgánico se descontroló con el agravamiento de problemas ya existentes: ocupación de áreas inundables escasamente accesibles y avance del deterioro ambiental.

De ahí en adelante, distintas corrientes de pensamiento y acción enmarcadas en la línea del "pensamiento único" y la cosmovisión de la globalización y el neoliberalismo del último cuarto del siglo XX nos han heredado una ciudad caracterizada por la retracción de su condición de "objeto público", más atomizada y disgregada, fragmentada según grupos socioeconómicos homogéneos, que conformaron su correlato físico a través de piezas urbanas dispersas sobre un tejido invadido por la irrupción de ellas mismas (CicColella, 1999).

Tras esta sucesión de avatares en la práctica de la política urbanística y el proceso de urbanización, en los cuales se han sucedido períodos de "hacer", "deshacer", "dejar hacer" y "volver a hacer", durante la segunda mitad del siglo XX (especialmente el último tramo), estaríamos volviendo a encontrarnos al inicio de una secuencia, en la posición del "volver a hacer" como rasgo característico del nuevo ciclo, iniciado en el primer decenio del siglo XXI, que podría llegar a ser pendular de no tomarse recaudos.

Cumplido tal ciclo, y a las puertas de uno nuevo, es posible establecer un balance respecto de las consecuencias en el territorio. Ese acontecer cíclico devolvería una visión desintegrada y caótica de la praxis sobre la ciudad, derivada de políticas públicas configuradas como respuestas coyunturales, difícilmente como soluciones planificadas de mayor plazo y con la complejidad necesaria.

\section{LA POLÍTICA PÚBLICA COMO HERRAMIENTA DE TRANSFORMACIÓN}

La política pública y el total de las prácticas urbanas se complementan y se contradicen según las diferentes formas que adoptan los modos de producción, uso y apropiación del espacio urbano y el sesgo del modelo de gestión política y económica de contexto. En ese marco, una multiplicidad de actores pugna por imponer en la agenda pública un modelo de gestión acorde con sus expectativas, condicionando el marco que el Estado asume para el desarrollo urbano. 
Las políticas públicas y económicas como marco de las políticas urbanísticas han oscilado entre un "hacer" de tipo "keynesiano" característico del Estado de Bienestar, hacia un "dejar hacer" apegado al neoliberalismo económico hacia fines del siglo XX, y se avizora un incipiente reinicio de similar ciclo en los albores del siglo XXI. Este vaivén de carácter cíclico ha inducido cambios estructurales en la configuración socioterritorial, con contrastes y contradicciones.

Se podrían construir cuatro visiones ${ }^{1}$ amplias (Rodulfo, 2005) acerca del rol de la administración estatal en política urbana en general, que condicionan la configuración de la ciudad y marcan las prerrogativas de la agenda urbanística.

* Voluntarista: el agente estatal dotado de la representación que le confiere ocupar un cargo en la administración pública se ocupa de la problemática y materializa cambios urbanos (mecanismos del "hacer").

* Determinista: el agente estatal participa activamente en la estructuración espacial deshaciendo lo que otros agentes construyeron (mecanismos del "deshacer").

* Refractaria: la agencia estatal reacciona pasivamente o posibilita el hacer del mercado o de otros agentes (mecanismos del "dejar hacer").

* Dispositiva: el Estado reasume funciones centralizando decisiones y desplegando acciones sobre el territorio que lo posicionan nuevamente en un rol activo ("volver a hacer").

Estas visiones contribuyen a entender la articulación Estado-Sociedad y el modo como los actores sociales construyen su propia cosmovisión en relación con la acción o inacción del Estado y con cómo este regula la producción del espacio urbano desde las políticas públicas.

Es justamente desde las políticas públicas que se interviene en la valorización del espacio y se establecen las condiciones para el desarrollo urbano, siendo factores relevantes en la determinación del uso y la apropiación diferencial de esa valorización la normativa urbanística y de Ordenamiento Territorial; los lineamientos, planes urbanos y regionales y proyectos urbanos; la obra pública en infraestructura básica y vial y equipamiento social; la política fundiaria y tributaria en relación con esta y la orientación de la política habitacional. El sentido, la magnitud y la intensidad de esos factores determinan el modo que adopta
1- Paráfrasis construida tomando como base la clasificación de Maria Beatriz Rodulfo en su texto Politicas Rodulfo en su texto Politicas habitacionales en Argentina. Estrategias y desafios, respecto del contexto sociopolítico en el cual se configuraron los rasgos característicos de las politicas habitacionales aplicadas en nuestro país desde la segunda mitad del siglo $X X$ 
el proceso de valorización del espacio urbano, en el que despliegan sus prácticas los agentes productores y los usuarios y consumidores (SzAJNBERG, CoRDARA y Bories, 2010).

Podría decirse que los preceptos de la planificación y de la disciplina urbanística más bien alcanzaron a influir desde contextos culturales en los cuales representaron un estereotipo, que por las acciones generales de control que de ellos debían necesariamente derivarse. Pero sí pueden verificarse influencias en algunas áreas de la ciudad, recostadas en la obra pública, a veces extemporánea y circunstancial, que promueven una evolución urbana errática, con formas de crecimiento que intercalan diferentes patrones de urbanización, motorizados por lógicas formales e informales, que han ido alternándose en cuanto a su prevalencia, según la evolución estructural de la práctica urbanística y de las diferentes coyunturas de las políticas públicas.

\section{Los mecanismos del hacer}

Los mecanismos del hacer llevados a la cuestión urbanística están identificados con una visión intervencionista y desarrollista, la cual se consolidó con el avance de la Industrialización por Sustitución de Importaciones y la figura del Estado Benefactor aportando a ese desarrollo, procurando regular los comportamientos urbanos a través de instrumentos técnicos de la política pública urbana. El Estado de Bienestar se fundó en el convencimiento de que era posible una intervención estatal que equilibrara el desarrollo y crecimiento económico y la redistribución social de recursos, con el apoyo de una planificación pública tecnocrática y centralizada. Para ello, el Estado debía ejercer un rol activo en la economía a través de la promoción y creación de empleo y al mismo tiempo, administrar satisfactores sociales, como la atención de la salud, la educación y la vivienda (CORDARA, SLimovich y otros, 2006).

En Argentina, la vivienda fue el tema casi hegemónico en la práctica profesional, así como también en las agendas públicas y urbanísticas. Por un lado, la Ley de Propiedad Horizontal en la década del 50 desencadenó una fuerte densificación vertical de las principales ciudades, especialmente en Buenos Aires, con el auge de los desarrollos inmobiliarios multivivienda en altura, que dio luego el típico tejido de edificios entre medianeras y en algunas zonas de la ciudad torres de vivienda, todo ello producido por inversiones privadas y apoyo crediticio del Banco Hipotecario Nacional.

Desde las políticas habitacionales, el Estado nacional interviene, con participación de las jurisdicciones federales, en la producción de vivienda social, determinando sus características y la población objetivo a través de una normalización de carácter "universal", prag- 
mático y funcional, proponiendo soluciones tipológicas prototípicas, que movilizaron la producción masiva y las economías de escala sobre el soporte del gran supuesto epocal que se recostaba sobre la idea de un proceso continuo de desarrollo tecnológico indefinido.

En la Región Metropolitana de Buenos Aires (RMBA), las políticas públicas consolidaron el crecimiento por expansión propiciando la baja densidad, con el fin de difundir la pequeña propiedad suburbana. Entre otras, estas políticas determinaron los préstamos subsidiados por bancos oficiales, las políticas tarifarias a nivel transporte público, el control de alquileres y el control del uso del suelo. Este modelo, caracterizado por los loteos económicos, dio acceso a la tierra a los sectores populares e hizo lugar al crecimiento de las industrias del primer y segundo cordón del área metropolitana, que apoyaban las políticas de sustitución de importaciones, con gran insumo de mano de obra y amplia expectativa de ascenso social, pero a su vez dejaban grandes problemas para el futuro en relación con la provisión de servicios e infraestructuras, ya que los trazados no tenían en cuenta los usos públicos.

Hacia mediados de la década del 60, ese modelo de ocupación se desaceleró. Ante graves situaciones derivadas de las inundaciones, se prohíben los loteos por debajo de la cota de inundación. Se implementa además un decreto (14381/68) que exige la provisión de infraestructuras básicas - agua corriente y desagües - en los nuevos fraccionamientos contiguos a las áreas urbanas (CLICHEvsky, 1987). Ya en la década del 70, se aplican planes para la construcción de grandes conjuntos residenciales reduciendo el crédito para la vivienda individual. ${ }^{2}$

Hasta aquí, esta exacerbación de la sistematización y el proteccionismo se desarrolló en un contexto sociopolítico que fomentaba la modernización a través de la industrialización y la urbanización. Esta coherencia funcionó mientras no cambiaron los esquemas de equilibrio de poder y también mientras se mantuvieron los crecimientos económicos derivados de la aplicación de políticas "keynesianas". Cuando el contexto cambió, emergió un nuevo paradigma, reflejo de la reestructuración económica que trastocó las economías cerradas y proteccionistas, volcándolas a otras desreguladas y neoliberales. Se iniciaba el pasaje de economías basadas en la producción de bienes a otras en las que prevalecerían las economías de especulación.

Los mecanismos del deshacer

El gran crecimiento demográfico de las ciudades industriales (consecuencia de las migraciones internas) y la expansión de la demanda y el consumo generados por las políticas "keynesianas" y desarrollistas requerían la figura del Estado Benefactor. Al entrar en crisis
2 Entre otros el conjunto La Rioja (1969), el conjunto Villa Soldati (1972), Lugano 1 y 2 , propiciando una ruptura con el tejido urbano tradicional y como laboratorios de urbanización de tierras despobladas, con altísimas densidades $y$ para población de escasos para población de escasos recursos económicos, que fueron moneda corriente en
la agenda política de los gobiernos anticonstitucionales hasta casi principios de la década de los 80. 
3- Globalización, políticas neoliberales, nuevas tecnologías en comunicación y en procesamiento de información, paradigma productivo "just in time", des-territorialización, flexibilización $y$ ajuste en paises no desarrollados.

4- Con características antipopulares y genocidas en el campo político, institucionaly social, y con uno de los mayores énfasis en la destrucción del pensamiento académico crítico y el exterminio y desaparición de gran parte de sus portadores. ese modelo a partir de la crisis mundial del petróleo y el cambio de paradigma productivotecnológico en el último cuarto del siglo $\mathrm{XX}^{3}$, el paradigma de Planificación Urbana de los "planes maestros-reguladores" y el modelo de producción de Vivienda de Interés Social (VIS) centralizado y a gran escala, con la figura del Estado como agente de financiamiento y producción, quedaron desactualizados y desmantelados.

A partir de entonces, y particularmente en nuestro país, es difícil establecer una línea clara en torno de las políticas públicas que marque contradicciones entre la planificación y la gestión; muy por el contrario, los modos de pensar y accionar sobre la ciudad resultaron lamentablemente coherentes, dado que se trata de un período atravesado por el más nefasto gobierno anticonstitucional (1976-1982). ${ }^{4}$ Pueden enunciarse algunas políticas urbanas que dan cuenta de ello, características de esta época del deshacer.

A nivel nacional, y en el marco del Sistema Nacional de Planeamiento y Acción para el Desarrollo - que entre otros aspectos regula el "derecho al espacio urbano"-, se emprenden obras urbanas de alto impacto y se implementan medidas que producen una fuerte presión sobre los sectores populares y dificultan su acceso al suelo urbano en Buenos Aires.

Algunos de los "hitos" en materia de política urbanística y habitacional de la época fueron los siguientes: destrucción del tejido urbano para dar lugar a la construcción de autopistas, destrucción del tejido productivo dentro de la ciudad de Buenos Aires, impedimentos para acceder a la compra de lotes con créditos en cuotas, por los altísimos intereses vigentes; Ley 1050 que reglamentaba la actualización de las tasas de interés —y que llevó a la ejecución de hipotecas de miles de viviendas y departamentos-; erradicación violenta de villas miseria. Muy particularmente, debe mencionarse que en este período se implementaron el Código de Planeamiento Urbano (CPU) en la ciudad de Buenos Aires (1977) y el Decreto Ley 8912 de 1979 de Ordenamiento Territorial y Usos del Suelo en la provincia de Buenos Aires, que aunque cuestionados en su eficacia, son los instrumentos que existen para regular el crecimiento urbano hasta la fecha. En particular, el planteo de la "8912" tiene dobles lecturas: mientras para unos se trató de consolidar el límite a la producción de loteos en el conurbano bonaerense, al exigir obras de infraestructura previas, y de limitar la subdivisión de parcelas rurales que estuvieran bajo cota de inundación, para otros, como consecuencia de este contexto, los sectores populares debieron desarrollar estrategias informales de acceso a la ciudad: densificación de formas de habitación precaria (villas miseria, inquilinatos y falsos hoteles en zonas centrales) y tomas masivas de tierras en forma organizada y ocupaciones de edificios en zonas centrales. Las tomas colectivas de 
tierras destinadas a asentamientos de viviendas por parte de sectores obreros, iniciadas a fines de 1981 y localizadas particularmente en zonas urbanas y periurbanas del Gran Buenos Aires, volvieron a expresar el surgimiento de movimientos sociales reivindicativos urbanos, luego de años de sometimiento y como emergente de un problema social que se había ido gestando como consecuencia de una trama de decisiones tomadas durante la Dictadura, que impactaron la vida y el hábitat popular.

Todo este proceso introdujo profundos cambios en el mercado de tierras en el área periurbana del conurbano bonaerense, provocando el abandono por sus propietarios de parcelas intersticiales, que hasta la Ley 8912 podían aumentar su valor con la "sola retención sin inversión" en espera del "avance de la urbanización", y en ese momento perdieron la posibilidad cierta de su valorización potencial, ampliando el espectro de vacancia y expansión de la urbanización que desde entonces no ha cesado. Este tipo de situaciones da cuenta además de la ambigüedad de algunos instrumentos urbanísticos y de ordenamiento territorial.

Los mecanismos del "dejar hacer"

La ciudad, entre tanto, comenzaba a ser librada a su suerte con la seguidilla de políticas que se iniciaron en el período del deshacer. En ese escenario - del cual fue partícipe la mayoría de los países latinoamericanos-, en Argentina se consolidan el desguace del Estado de Bienestar y una fuerte desindustrialización que luego se reafirmarían mediante la Reforma del Estado y medidas como la Convertibilidad Cambiaria desde lo económico, en la última década del siglo XX.

Si bien se abre una etapa de transición debido al retorno de la democracia a inicios de los 80 , lo que conlleva como resultado un cambio de perspectiva, hecho que se expresa en una renovada tolerancia en relación con la problemática de la vivienda, como contrapartida y emergente colateral indeseado esto provocó que las ocupaciones informales y precarias se intensificaran. La crisis económica derivada de las políticas de ajuste produce cambios institucionales, centralizando las inversiones en lo local y propiciando la actuación de organizaciones intermedias y de base, en lucha por el espacio. El resurgimiento de la sociedad civil deviene del desprestigio del Estado autoritario y las debilidades del Estado de Bienestar, presuponiéndose que la consolidación de la democracia generaría crecimiento y bienestar.

Lo cierto es que la crisis social, política y económica que había llegado entonces no pudo contenerse frente a la espectacular retracción del sector público, y el "pensamiento único" característico del último tramo del siglo XX ganó espacio en las agendas de la política pública urbana. 
Si bien tanto el hacer como el deshacer implican que el Estado asume un rol que procura activar mecanismos para poder arbitrar la ruptura del orden preestablecido, para el caso del dejar hacer, el Estado también opta, aunque procurando un desentendimiento de sus responsabilidades indelegables, trasladándolas a la esfera del mercado. Los grandes temas de la Planificación, como el control demográfico, las infraestructuras y servicios y también la Vivienda, fueron alejados de las agendas y de la gestión urbanística.

Como contracara de ello se produce un incremento de la masa poblacional en condiciones sociohabitacionales deficitarias y de pobreza estructural, resultante de las políticas de ajuste, la reforma del Estado y el modelo económico neoliberal imperante en los años 90.

Este nuevo modelo de Estado de intervención mínima significó no solo una reducción del gasto público, de las estructuras burocráticas y una descentralización administrativa, sino que produjo el vaciamiento de las capacidades institucionales del Estado en su rol de organizar y regular el funcionamiento, producción y reproducción social. El aumento de la desocupación y la reestructuración del mercado laboral hicieron necesario que el Estado asumiera un rol asistencialista al tener que crear y reforzar estrategias de contención a la pobreza a través de políticas sociales focalizadas.

En un clima de creciente pobreza y desarticulación social, se acentuaron en forma cíclica las ocupaciones de tierras. Los grupos de pobladores que han encontrado en esta estrategia la única vía posible de acceso al suelo urbano desarrollaron una intensa actividad para cubrir los déficit que este presenta (servicios, ordenamiento territorial, regularización dominial, equipamiento comunitario, etc.), configurando su forma de "producir ciudad". Estos asentamientos son concebidos y llevados adelante por sus habitantes con el propósito de integrarse a la ciudad, de convertirse en propietarios y alcanzar la situación de "legalidad". Sin embargo, esa formalización no es simple de gestionar y no siempre es posible alcanzarla. Así, la informalidad en las soluciones habitacionales alcanzó extremos desconocidos hasta entonces, no solo por la masividad del proceso, sino también por los altos niveles de indigencia, marginalidad y exclusión.

La consecuencia de las contraposiciones que las tres fases que conforman el ciclo descrito han impreso al modelo de crecimiento es que a pesar de las políticas públicas que seguramente procuraron moldear otro modelo de ciudad, se ha llegado a una ciudad a la que un proceso de crecimiento rápido y dinámico la llevó a una configuración en mancha de aceite, extendida y de baja densidad, escasa de infraestructuras y servicios, donde el espacio urbano decae. 
Partiendo de la hipótesis que define que tanto el control de la expansión como la maximización de las densidades son algunos de los aspectos más importantes del hecho urbano, podríamos considerar los dichos de Peter Hall respecto de que cuando las lecturas arrojan marcados desequilibrios, polarizaciones, discontinuidades y fragmentaciones, divergencias díscolas sin jerarquías territoriales, seguramente nos enfrentamos con un organismo enfermo.

\section{LA CIUDAD EN EL COLUMPIO. LOS DESAFÍOS EMERGENTES DEL AMBA}

La evolución territorial de Buenos Aires ha ido pendulando entre extremos en los que se manifiestan acciones intervencionistas de un Estado Benefactor hasta un derrotero de desguace de esas mismas acciones, entregando la ciudad a los agentes de producción del mercado y librando a su suerte a un gran contingente poblacional que debió aguzar sus estrategias de producción del hábitat, en general desde la informalidad.

Sometida a ese vaivén pendular, la ciudad ha resuelto su fisonomía condicionada por políticas y prácticas urbanas confusas, sin prelación en las decisiones o las consecuencias emergentes, abandonada a su suerte. Si bien el proceso ha sido espontáneo y circunstancial, pueden constituirse patrones de desarrollo que caracterizan épocas en forma más o menos evidente.

Pueden verificarse dos períodos distintivos en los rasgos estructurales. Si bien existe una primera instancia definida por un patrón territorial derivado del modelo agroexportador, que forjó la matriz colonial ferroviaria con un crecimiento urbano a lo largo de ejes estructuradores ferroviarios, el primer período significativo con incidencia en los aspectos de la urbanidad está asociado con el crecimiento demográfico exponencial de las ciudades, derivado del proteccionismo en el que entraron los estados luego de la crisis económica mundial de 1929. Esta modificación, si bien puede expresar un nuevo modelo territorial derivado de una reconfiguración productiva aplicada en el contexto de la Industrialización por Sustitución de Importaciones, da cuenta de que ese cambio es de índole cuantitativa, en tanto el modelo mantuvo su conformación previa en esencia. El desarrollo de la nueva matriz productiva y las actividades asociadas se apoyaron en la infraestructura del modelo de producción primaria para desarrollar el sector industrial y el terciario. El crecimiento urbano siguió marcando su estructura sobre ese soporte físico radio-concéntrico y consolidó su morfología en estrella, con los mayores atributos urbanos cercanos a la centralidad original y conformando bolsones de precariedad en los intersticios y en los bordes de la conurbación, aunque esa cualidad cambiaba de manera ascendente en forma muy dinámica en tanto el Estado mantuvo un rol activo de carácter intervencionista y regulador. 
El arco temporal de esta estructura alcanza más de medio siglo de expansión, hasta entrada la década del 70, cuando se consolidó un modelo espacial que crecía a través del módulo "manzana", que pregonaba la continuidad y conformaba una homogeneidad de tejidos que propiciaban una ciudad abierta y policlasista, con centralidades jerarquizadas en función de accesibilidades colectivas masivas, con altas expectativas de movilidad social ascendente como resultado del imaginario del Estado Benefactor, capaz de generar acciones de intervención en el ordenamiento territorial, en tanto la ciudad también se expandía de manera desordenada a partir de la urbanización espontánea por vía de loteos populares.

Un nuevo ciclo refleja y manifiesta una ruptura en el modelo territorial, asociada con una reconfiguración económico-productiva y con el cambio de paradigma cultural y productivo, que se inicia en los 70 y se consolida en la década del 90.

El modo de abordaje y comprensión puramente cientificista y racional, apegado a visiones modernas que sostenían el modelo de desarrollo indefinido mediante la industrialización y la explotación de los recursos naturales, entró en crisis. Las ciencias positivistas comenzaron a ser desplazadas por posicionamientos críticos, que evidenciaron los efectos residuales y sobre todo las crisis sociales y territoriales que dejaron como consecuencia los efectos colaterales del desarrollo impulsado por el Estado Benefactor y Desarrollista. Dichas críticas incluso aparecieron evidenciando las inequidades del crecimiento aun antes del abandono de las políticas de producción de tipo fordista.

Así el modelo dejó de reposar sobre la articulación de variables estáticas, empíricas y positivistas, y comenzó a poner énfasis en el análisis de los procesos sociales subyacentes, más que en las estructuras espaciales resultantes.

Las nuevas formas apuestan por un modelo opuesto al de hasta entonces, lo que genera un fuerte contraste respecto de la estructura que aún hoy persiste y prevalece. La fragmentación y segregación, la heterogeneidad y la ruptura, la aparición -y ahora afianzamiento- de nuevas centralidades con accesibilidades privativas y clasistas, una ciudad cerrada con tendencia a la prevalencia del espacio privado por sobre el público, con un Estado en retirada, al menos hasta entrado el nuevo milenio y cediendo protagonismo al mercado, son los atributos del nuevo modelo de desarrollo territorial encaballado entre fines del siglo XX y principios del XXI.

Pero ¿qué modelo terminó primando en términos de mancha urbana en relación con la ocupación del territorio? 
Según lo publicado en los Lineamientos Estratégicos para la RMBA (2007), para mediados de los años 60, la forma que adquiría la estructura urbana consolidaba y profundizaba la compacidad tentacular que se apoyaba en la disposición de los ejes ferroviarios heredados del período anterior. Para ese entonces, la ciudad contaba con 8 millones de habitantes distribuidos en $800 \mathrm{~km}^{2}$.

En las décadas siguientes, este fenómeno de compacidad comienza a perder peso como resultado de la ocupación de los intersticios dejados entre los ejes de poblamiento anteriores. La instalación de industrias en las áreas intersticiales, que muchas veces coincidían con los valles de inundación, contribuyó a descomprimir la compacidad antes mencionada y a expandir la mancha urbana. Para ese entonces (fines de los 80) el AMBA se desarrollaba sobre $1800 \mathrm{~km}^{2}$ y contaba con 11 millones de habitantes. El descenso de la densidad poblacional en conjunto determinó que las áreas suburbanas crecieran sin articulación entre sí, y desprovistas en la mayoría de los casos de la infraestructura básica.

"El atributo de compacidad fue entonces mutando hacia cierta fragmentación y polarización, con la aparición de áreas con mejor conectividad y accesibilidades, con heterogeneidades en los indicadores socio-habitacionales y la aparición de enclaves clasistas y subcentralidades urbanizadas con territorios de baja densidad con escasas infraestructuras y servicios" (SZAJNBERG, CORDARA, Bories, 2010).

En los últimos años del siglo XX la mayor metrópolis del país experimenta profundos cambios morfológicos, estructurales y de relaciones sociales que no hacen más que agravar los contrastes que ya se venían vislumbrando. Se acrecientan problemas tales como el acceso a la vivienda de los sectores más desfavorecidos, ocupación de áreas inundables escasamente accesibles, déficit del transporte y de los espacios públicos.

En síntesis, se profundiza un proceso de segregación socioterritorial en el que los desajustes y la oferta de bienes y servicios urbanos marcan situaciones como nunca antes vistas.

Este nuevo patrón de metropolización diferencial expone la ausencia de políticas públicas tendientes a generar el equilibrio necesario para el desarrollo equitativo de la ciudad. Los espacios del mundo globalizado en el mercado residencial se apoyaron en una plataforma de nuevas redes de interconexión. Se realizaron grandes inversiones en obras viales y se ampliaron, remodelaron y desarrollaron nuevas redes de autopistas (MignaQui y SZAJNBERG, 2003). 
La consecuencia física del contexto social, político, económico, cultural y tecnológico descrito es una nueva forma de metropolización que ha producido una alteración del patrón de urbanización metropolitano vigente hasta los años 70 (ToRREs, 1997). Este espacio definido por sus discontinuidades, con un alto impacto sobre el periurbano, profundiza la relación entre el espacio consumido y el territorio realmente ocupado. Según datos manifiestos en la fuente citada precedentemente, en la actualidad el AMBA se expande en alrededor de $14.000 \mathrm{~km}^{2}$, donde viven 14 millones de personas, mostrando áreas densamente pobladas y otras con baja densidad poblacional.

Esta nueva dinámica de crecimiento coexiste con el patrón de desarrollo territorial preexistente, es decir que el crecimiento por extensión de baja densidad continúa desarrollándose apegado a otra ciudad, que es la misma, aunque esta se dimensiona desde la lógica del enclave.

Por una parte tenemos el crecimiento mediante enclaves; por otra, la dispersión territorial difusa, aunque continua en algún grado con la mancha homogénea consolidada. Ambas formas se definen contrapuestas y se vuelven más evidentes por la distancia y el vacío que generan grandes intersticios periurbanos, relegados de los desarrollos urbanos privados, por lo general desconectados y sin infraestructuras jerarquizadas de conectividad.

Los mayores desafíos se encuentran sobre el control de la expansión, y es básicamente en el periurbano donde esos contrastes aparecen con mayor claridad. Allí prevalecen configuraciones no homogéneas, alejadas de las lógicas de planeamiento emanadas de las leyes de ordenamiento territorial, y es donde la presión sobre el mercado de tierras por parte de los distintos actores sociales y políticos despliega su dinámica sectorial, disponiendo y sometiendo a la extensa geografía del territorio a una continua desventura en cuanto al manejo de su destino planificado.

En tanto la ciudad se corre hacia una periferia anodina evadiendo sus centralidades y se amplían sus territorios selectos conformando un escenario urbano segregado, se muestra como contracara un universo magnificado de exclusión social. Como si no hubiera transcurrido el tiempo y no hubiésemos aprendido tras más de dos siglos de historia urbana desde la Revolución Industrial, volvemos al punto de partida, lugar desde el cual — parece- poco han influido las políticas públicas para afrontar la responsabilidad del Estado como articulador de las pujas sociales en el espacio urbano.

Tras varias décadas de políticas neoliberales y un contexto mundial sesgado por los procesos de globalización y reestructuración económica, han surgido marcadas transformaciones 
ambientales y socioespaciales. Una de las problemáticas agudizadas es la del crecimiento del hábitat precario, la profundización de la segregación socioterritorial y una interacción socioambiental lacerante.

Incremento del déficit habitacional, conflictos por el aumento de la brecha entre sectores socioeconómicos extremos y el retroceso del Estado han sido los fenómenos que promovieron nuevas dinámicas de ocupación territorial y producción de soluciones habitacionales informales. ¿No estamos entonces donde empezamos? Así parece.

\section{URBANISMO SECUENCIAL. LA GESTIÓN DEL TERRITORIO EN UN CONTEXTO DE INCERTIDUMBRE}

¿Qué nos depara este incipiente y nuevo inicio de ciclo?

El análisis de estos ciclos, de idas y vueltas, pone de relieve que la dinámica de los procesos sociales y económicos, cuando no son acompañados de acciones claras de gestión y planificación urbana, genera una estructura socioterritorial compleja y fragmentada.

La incertidumbre y la multiplicidad de las variables que se interrelacionan en el espacio urbano obligan a replantear los mecanismos de lectura sobre la ciudad. Ya no solo se perciben como necesarias las rupturas entre las secuencias consecutivas, sino que, además de la falta de la lógica de concatenación, aparecen distintas cadenas secuenciales con otras variables de similar valor de impacto, no siendo posible establecer subsidiariedades entre ellas.

Sumado al hecho de que las relaciones causa-efecto no se repiten, puede observarse que los resultados y comportamientos son en algunos casos impredecibles, pasando de un esquema de entendimiento, acción y resultado "complicado" a otro de naturaleza "compleja".

Más que una mirada propositiva desde el territorio y su lectura de problemas mediante la extensiva realización de un puntilloso diagnóstico, se trata de establecer posturas críticas de los procedimientos, para conseguir revertir esos problemas. Es una especie de revisión de los modos de pensar y producir las ciudades, mediante la cual se apuesta a repensar las acciones de transformaciones espaciales y sociales con nuevos modos de pensar los procesos urbanos.

Entendidos el pensamiento y la acción sobre el territorio como un sistema complejo, es necesario comprender la realidad desde una mirada diversa, sistemáticamente integrada, 
permeable, comedida y prudente, conceptualmente abierta, paulatinamente dispuesta e involucrada, ambientalmente sustentable, actoralmente integradora, socialmente renovadora, económicamente viable, rigurosamente controlada, eficazmente gestionada y como consecuencia, progresivamente justa y estructuradamente equitativa.

Para ello, resultaría clave no repetir las mismas operaciones para no recaer en similares síntomas. Al inicio de este nuevo ciclo del "volver a hacer", que toma como punto de inflexión la crisis argentina del año 2001, el modelo económico basado en la apertura económica, la flexibilización y el ajuste estructural, entre otros, entraró en crisis por sus consecuencias sobre la situación socioeconómica de la población y la credibilidad de las instituciones políticas. También entró en crisis el paradigma de la "ciudad fragmento", y el contraste entre los nuevos enclaves residenciales y espacios de consumo de la población de mayor nivel socioeconómico entraría en crisis con el creciente espacio de la pobreza, manifiesto en la densificación de las villas de emergencia existentes, la proliferación de nuevos asentamientos informales precarios, el incremento de la población en inquilinatos, pensiones, hoteles e inmuebles tomados, en situación de calle y en condiciones de extrema pobreza e indigencia.

"Desde lo instrumental, es preciso habilitar nuevos instrumentos de gestión y control para accionar la transformación, apostando a la implementación de un 'Urbanismo Secuencial'”' (SZAJNBERG, CORDARA y Bories, 2010). Este tipo de urbanismo deja la puerta abierta a la no-linealidad de los sucesos y procesos y pone en escena la idea de que las interrupciones o hechos que alteran lo programado constituyen una oportunidad para mirar la intervención de manera flexible. Es decir, buscar una readaptación de las nuevas variables que aparezcan para poder dar respuesta a las demandas que les dieron origen.

En este sentido, es válido proponer un modelo de gestión urbano posible, que articule los lineamientos generales con la acciones que promuevan la transformación de los sectores clave del territorio, "proponiendo sumatorias de sucesivas intervenciones secuenciales que puedan sostenerse en el largo plazo, estructuradas por las definiciones de un plan urbano". (SZAJNBERG, CORDARA y Bories, 2010). Esto permitiría brindar respuestas acordes con la velocidad y complejidad de los hechos y procesos urbanos, siempre definidas en el marco de actuación de estrategias totalizadoras que dispongan su coherencia de base como plataforma para la implementación de las intervenciones. 


\section{BIBLIOGRAFÍA}

CASTELLS, M., (1972-4) La cuestión urbana, Siglo XXI Argentina Editores (1. a Ed. México).

CICCOLELLA, P. (1999). "Grandes Inversiones y Reestructuración Metropolitana en Buenos Aires: ¿Ciudad global o ciudad dual del siglo XXI?”. En: V Seminario Internacional de la RII, Toluca, México.

CLICHEVSKY, N. (1987). "Política urbana y mercado de tierra, Buenos Aires 19701986". En: Boletín de medio ambiente y urbanización, número especial, Buenos Aires.

CORDARA, C., SLIMOVICH, E., HUGUES, V., LIZZA, M., RUFFINELLI, M., (2006) El movimiento pendular de la política habitacional. El caso del barrio Villa Palito en la Matanza. Inédito. PROPUR. Buenos Aires.

HALL, P. (1996) Ciudades del mañana. Historia del urbanismo en el siglo XX, Editorial del Serbal, Barcelona.

MIGNAQUI I. y SZAJNBERG D. (2003). "Tendencias en la organización del espacio residencial de la RMBA en los noventa”. En: Procesos territoriales en Argentina y Brasil, A. Fani Alessandri Carlos y R. Bertoncello comp. Departamento de Geografía, Universidad de San Pablo e Instituto de Geografía, UBA, Buenos Aires.

RODULFO, M.B. (2005). "La evolución de la gestión en políticas habitacionales y su relación con el desarrollo local. El caso argentino”. Análisis comparativo de modelos de gestión. XI Encuentro Red ULACAV «Experiencias académicas para la gestión social del hábitat». Rosario, Provincia de Santa Fé.

SUBSECRETARÍA DE DESARROLLO URBANO Y VIVIENDA (2007). "Lineamientos Estratégicos Para La Región Metropolitana De Buenos Aires"; Dirección Provincial de Ordenamiento Urbano y Territorial. Gobierno de la provincia de Buenos Aires.

SZAJNBERG, D; CORDARA, C. y BORIES, C. (2010). "Balance de las estrategias de Intervención urbanística en los albores del siglo XXI". Scripta Nova. Revista Electrónica de Geografía y Ciencias Sociales. [En línea]. Barcelona: Universidad de Barcelona, Vol. XIV, N..$^{\circ} 331$ (24).

TORRES, H. (1997): “Transformaciones socioterritoriales recientes en una metrópoli latinoamericana. El caso de la aglomeración Gran Buenos Aires", en 6. EGAL Territorios en Redefinición. Lugar y Mundo en América Latina, Instituto de Geografía, FFyL-UBA, Buenos Aires. 


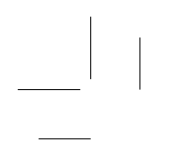

1 -

$\overline{-}_{11}$

II 